\title{
STUDY OF ATMOSPHERIC INSTABILITY OF JUNE IN THE PERIOD 2004-2019 IN THE NORTH-WESTERN REGION OF ROMANIA
}

\author{
Narcis MAIER ${ }^{1}$, A. MAIER ${ }^{2}$ \\ DOI: 10.24193/AWC2020_25
}

\begin{abstract}
The meteorological radar, due to its temporal and spatial resolution, has become an indispensable and necessary tool in the meteorologist's hand in order to create a climatology of the meteorological phenomena, to identify synoptic-orographic mechanisms that lead to their appearance and timely issue of weather alerts. This is observed from the analysis of June between 2004 and 2019 with the help of the WSR98D radar from Bobohalma near Târnăveni. Using certain radar parameters: reflectivity, hail size, the number of identified storms, the years were ranked according to their atmospheric instability, in order to compare them with climatological data. Thus it was obtained that in the years 2018, 2016 and 2019 the atmospheric instability the highest of, obtaining a good correlation with the average deviations of the geopotential at 500 $\mathrm{mb}$ and of the isotherms at $300 \mathrm{mb}$ and $850 \mathrm{mb}$ or with the low values of the LI index (instability index).
\end{abstract}

Keywords: atmospheric instability, radar, storms, reflectivity, North-Western of Romania

\section{INTRODUCTION}

The degree of atmospheric instability of a day or a month is often very difficult to estimate because the data from the weather stations are at isolated points which may or may not capture a meteorological phenomenon or its intensity. In order to cover this shortcoming, the weather radar WSR-98D Bobohalma (near Târnăveni) was used, which by its temporal and spatial resolution was able to identify the meteorological phenomena, characteristic of instability, in evolution as well as their intensity. Hence, it is necessary to create a radar climatology using data provided by the Doppler WSR-98D radar. The purpose of this paper is to provide a comprehensive statistical analysis of convective storms from the north-western part of Romania in June between 2004 and 2019. While radar data is widely used for short-term weather forecasting, climate use is still uncommon. An analysis of climatic studies for Europe using meteorological radar data was carried out by Keuppet al. (2017) showing that there are only a few of such studies, the majority of the works being related to hail or precipitation.And yet, radar data

${ }^{1}$ ANM Bucuresti - CMR Transilvania Nord, Cluj-Napoca, Romania, e-mail: mcis73@yahoo.com

${ }^{2}$ Babeş-Bolyai University, Faculty of Mathematics, Cluj-Napoca, Romania, 
has many advantages over other sources. Radar-based data allow the study of small-scale atmospheric structures and dynamics (Berg et al. 2015). All in all, radar data has great potential for climatological applications, which is far from being fully exploited. Thus, this paper aims to provide a perspective on the possibilities of the climatological use of meteorological radar data in estimating the degree of atmospheric instability.

\section{DATA AND METHODS}

The data received from the S-band Doppler Radar, type WSR-98D, installed at Bobohalma (RDBB) were used in analyzing16 summer seasons, June 2004 - 2019. The coverage area of the RDBB is $166106 \mathrm{~km}^{2}$. An application of the WSR radar identifies a possible storm according to certain parameters of the cloud system, such as reflectivity, echo height, liquid composition, or ice etc. Thus, when a cloud or a cloud system that is identified meets these characteristics, it receives a name (e.g. A2) and it is also called "storm core". Data on these storm cores are available every 6 minutes and contain information such as: coordinates of the core (name, radius and azimuth), type of core (Meso or TVS), hail probability (POSH Probability of Severe Hail and POH-Probability of Hail), hail size, VIL (vertically integrated liquid), maximum reflectivity and the height at which it is found, the height of the cloud top, predicted direction and propagation speed. Polar coordinates were transformed into scalar coordinates to facilitate analysis.

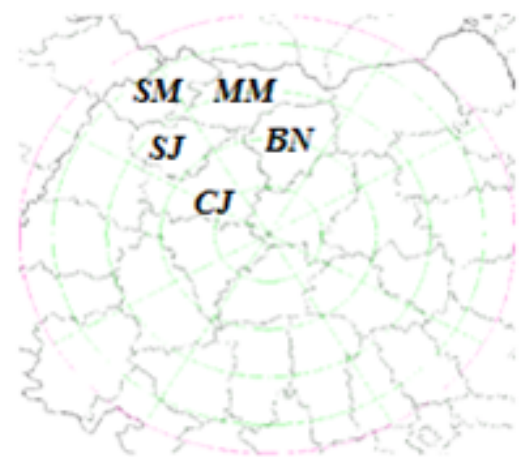

Fig. 1. Radar reception area by Bobohalma WSR-98D

In 16 years, the RDBB radar identified a number of 905624 storms out of which 306361 storms were analyzed, only those located to the north-west of the radar site in the area of Cluj (CJ), Salaj (SJ), Satu Mare (SM), Maramures (MM) and Bistrita Nasaud (BN) counties. (Fig.1) The ranking was made according to the number of storms, so the year with the most storms received rank 16 and the year with the fewest storms received rank 1 . The analysis was performed both quantitatively and qualitatively. The average number of storms in a day was about 640 , so it was one of the criteria to identify how many days exceeded this average. Then the analysis was made according to the number of days in which were recorded over 1200 storms. The number of storms of 1200 is chosen arbitrarily being almost double than the average 
of the day.The ranking was made beginning with the year with the most days with storms that received 16 points. The qualitative analysis was done according to the maximum reflectivity identified by the radar for each storm, taking the threshold of $55 \mathrm{dBZ}$ level from which it is considered that the storm is mature, and the size of the hail determined by the radar taking as the threshold the diameter of $2 \mathrm{~cm}$.

Using data from https://www.esrl.noaa.gov/there were analyzed the monthly deviations of the geopotential height from $500 \mathrm{mb}$ and of the isotherms from 300 $\mathrm{mb}$ to $850 \mathrm{mb}$, the top was made according to the size of the negative or positive deviation. The highest score (16 points) was received by the highest positive deviation and the lowest score (1 point) by the highest negative deviation. Also, through the data from noaa.gov there was analyzed the monthly evolution of the LI index (lifted index), an instability index. The year with the lowest value of LI received the maximum score of 16 points.

\section{ASSESSMENT OF THE ATMOSPHERIC INSTABILITY WITH RADAR DATA}

The assessment of atmospheric instability degree was made using data from the Doppler radar from Bobohalma near Târnăveni. The analysis was done quantitatively using the number of storms detected by the radar monthly and daily in June 2004-2019.The analysis for each day was made according to the average value for June of 640 storms and the value of 1200 storms. The qualitative analysis was done taking into account the maximum reflectivity of each storm, andconsidering only the mature storms with reflectivity greater than $55 \mathrm{dBZ}$ or that had a hail diameter of more than $2 \mathrm{~cm}$.

\subsection{Assessment of atmospheric instability based on the number of storms detected by radar per month}

WSR-98D radar has identified 306361 storms. At every 6 minutes scan, the radar identifies cloud formations that, depending on their characteristics, can be considered storms. (Fig. 2)

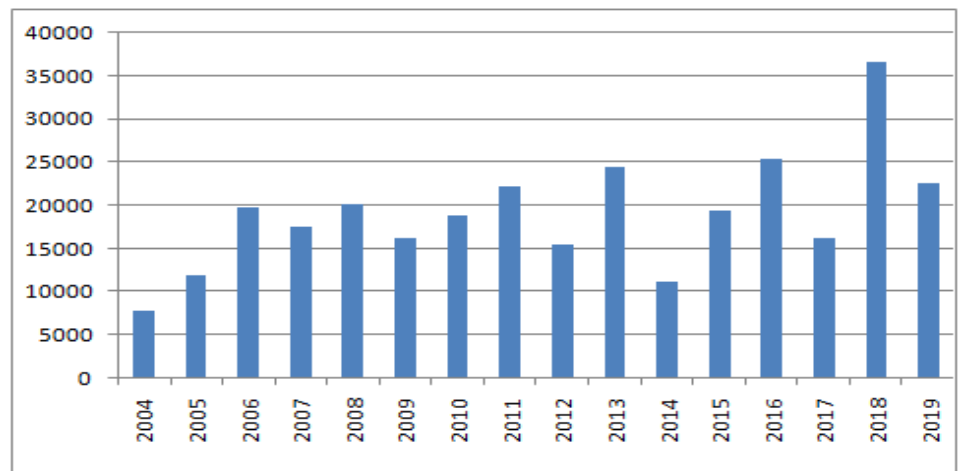

Fig. 2. Number of storms detected by Bobohalma WSR-98D radar in June between 2004 and 2009. 
Points from 1 to 16 were given according to the number of storms detected by Bobohalma WSR-98D radar in June between 2004 and 2009. (Table 1)

Table 1. Instability rank according to the number of storms

\begin{tabular}{|c|c|c|c|c|c|c|c|c|c|c|c|c|c|c|c|c|}
\hline Year & 2018 & 2016 & 2013 & 2019 & 2011 & 2008 & 2006 & 2015 & 2010 & 2007 & 2009 & 2017 & 2012 & 2005 & 2014 & 2004 \\
\hline $\begin{array}{c}\text { Number } \\
\text { storms }\end{array}$ & 36602 & 25484 & 24537 & 22604 & 22180 & 20246 & 19816 & 19417 & 18788 & 17614 & 16212 & 16321 & 15436 & 11885 & 11307 & 7912 \\
\hline Rank & $\mathbf{1 6}$ & $\mathbf{1 5}$ & $\mathbf{1 4}$ & $\mathbf{1 3}$ & $\mathbf{1 2}$ & $\mathbf{1 1}$ & $\mathbf{1 0}$ & $\mathbf{9}$ & $\mathbf{8}$ & $\mathbf{7}$ & $\mathbf{6}$ & $\mathbf{5}$ & $\mathbf{4}$ & $\mathbf{3}$ & $\mathbf{2}$ & $\mathbf{1}$ \\
\hline
\end{tabular}

Thus, from the storms number point of view, the years 2018, 2016, 2013, 2019 have higher ranks and 2005, 2014 and 2004have lower ranks.

\subsection{Assessment of atmospheric instability based on the number of storms detected by radar per day}

Only the number of storms is not sufficient to determine the degree of the atmospheric instability of the month. In how many days were the storms present? The average number of storms per day was calculated for the entire considered period obtaining an average number of storms of 640 per day. (Fig.3)

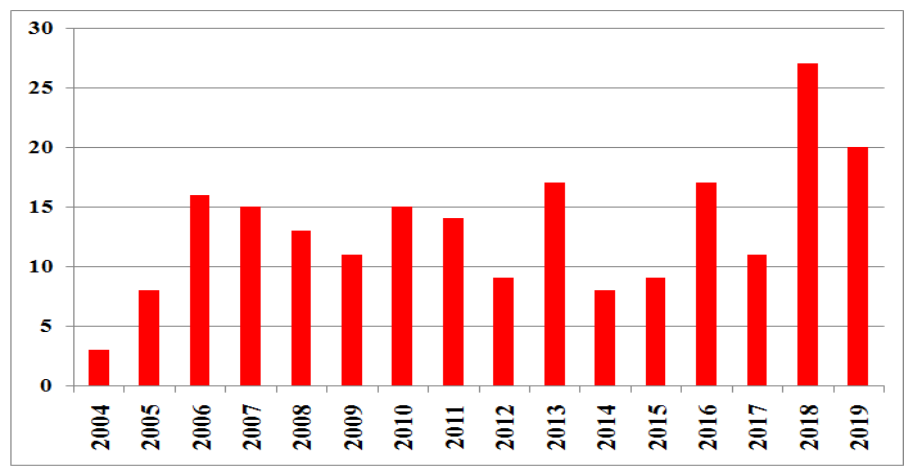

Fig.3. Number of days with more than 640 storms detected by Bobohalmathe WSR-98D radarin June between 2004 and 2009.

The years 2018, 2019, 2016, 2013 rank among the first in the top when in June are many days with above average atmospheric instability. The year 2018 has 27 days with above average atmospheric instability. But a slight change in the top is observed, and not only in the first 4 years. So, the degree of instability is also given by the number of storms in a day. (Table 2)

Table 2. Atmospheric instability rank according to the number of days with more than 640 storms

\begin{tabular}{|c|c|c|c|c|c|c|c|c|c|c|c|c|c|c|c|c|}
\hline Number days & 27 & 20 & 17 & 17 & 16 & 15 & 15 & 14 & 13 & 11 & 11 & 9 & 9 & 8 & 8 & 3 \\
\hline Year & 2018 & 2019 & 2016 & 2013 & 2006 & 2007 & 2010 & 2011 & 2008 & 2009 & 2011 & 2012 & 2015 & 2005 & 2014 & 2004 \\
\hline Rank & $\mathbf{1 6}$ & $\mathbf{1 5}$ & $\mathbf{1 4}$ & $\mathbf{1 3}$ & $\mathbf{1 2}$ & $\mathbf{1 1}$ & $\mathbf{1 0}$ & $\mathbf{9}$ & $\mathbf{8}$ & $\mathbf{7}$ & $\mathbf{6}$ & $\mathbf{5}$ & $\mathbf{4}$ & $\mathbf{3}$ & $\mathbf{2}$ & $\mathbf{1}$ \\
\hline
\end{tabular}


Doing a refining (Fig. 4), ranking was made according to the number days with more than 1200 storms, we get essential changes especially in the middle of the ranking (Table 2, Table 3).

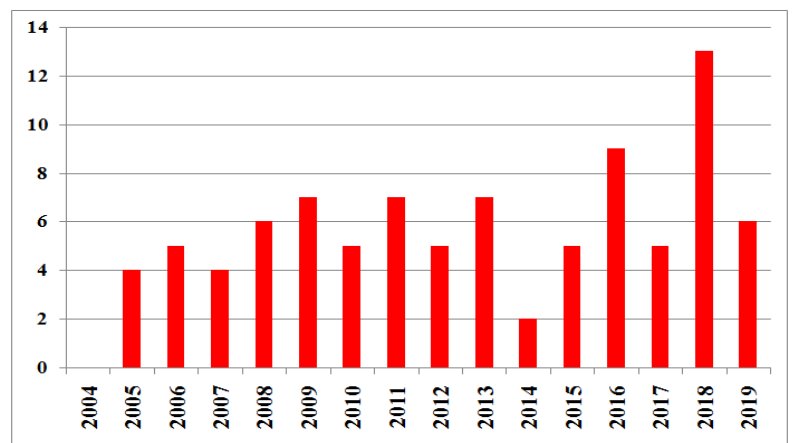

Fig. 4. Number of days in Junewith more than 1200 storms detectedby BobohalmaWSR-98D radarbetween 2004 and 2009.

Fixing an upper threshold, it was sought to establish a ranking of the intensity of the degree of atmospheric instability. The most spectacular jump is observed in the year 2019. If at the first 2 criteria it was in the top, at the criterion of over 1200 storms it falls on the 10th position, decreasing from 20 days to 6 .

Table3. Instability rankaccording to the number of days with more than 1200 storms in June

\begin{tabular}{|c|c|c|c|c|c|c|c|c|c|c|c|c|c|c|c|c|}
\hline Number days & 13 & 9 & 7 & 7 & 7 & 6 & 6 & 5 & 5 & 5 & 5 & 5 & 4 & 4 & 2 & 0 \\
\hline Year & 2018 & 2016 & 2009 & 2011 & 2013 & 2008 & 2019 & 2006 & 2010 & 2012 & 2015 & 2017 & 2005 & 2007 & 2017 & 2004 \\
\hline Rank & $\mathbf{1 6}$ & $\mathbf{1 5}$ & $\mathbf{1 4}$ & $\mathbf{1 3}$ & $\mathbf{1 2}$ & $\mathbf{1 1}$ & $\mathbf{1 0}$ & $\mathbf{9}$ & $\mathbf{8}$ & $\mathbf{7}$ & $\mathbf{6}$ & $\mathbf{5}$ & $\mathbf{4}$ & $\mathbf{3}$ & $\mathbf{2}$ & $\mathbf{1}$ \\
\hline
\end{tabular}

\subsection{Assessment of atmospheric instability based on the maximum reflectivity $>55 \mathrm{dBZ}$}

By analyzing the storms qualitatively, i.e. we use the intensity of the storms, it is observed that out of the total number of storms, only $14.8 \%$ become mature and can cause damage. A mature storm is considered to have a reflectivity greater than 55 dBZ. (Fig. 5)

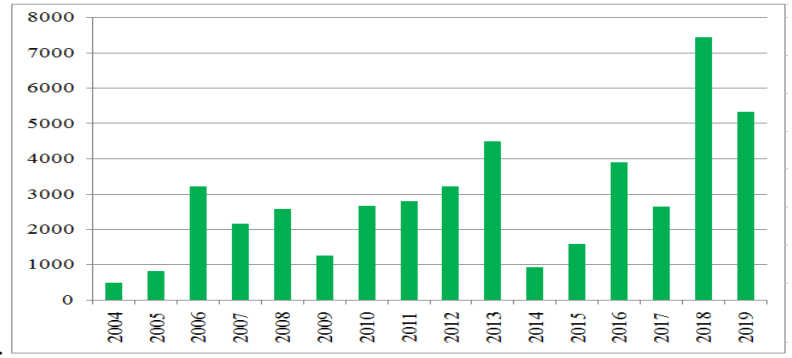

Fig. 5. Number of storms with reflectivity $>55 \mathrm{dBZ}$ detected by Bobohalmathe WSR-98D radarin June between 2004 and 2009. 
A new ranking is made according to the number of storms with reflectivity $>55 \mathrm{dBZ}$ detected by Bobohalma the WSR-98D radar in June between 2004 and 2009. (Table 4). Again the ranking of the unstable years keeps in the top the years 2018, 2019.

There are differences from the other charts. The year 2009goes to the end of the ranking with 11 positions when considering only mature storms. Analyzing the storms, it is obtained that there were years when in June there were many storms but not all were intense and years with fewer storms but with a higher frequency of mature storms (Table 3). For example, the 2019 year goes from the 6th position to the 2 nd one, which shows us that the storms were generally more intense.

\section{Table 4. Atmospheric instability rank according to the number of storms with reflectivity $>55 \mathrm{dBZ}$}

\begin{tabular}{|c|c|c|c|c|c|c|c|c|c|c|c|c|c|c|c|c|}
\hline Year & 2018 & 2019 & 2013 & 2016 & 2006 & 2012 & 2011 & 2010 & 2017 & 2008 & 2007 & 2015 & 2009 & 2014 & 2005 & 2004 \\
\hline Rank & $\mathbf{1 6}$ & $\mathbf{1 5}$ & $\mathbf{1 4}$ & $\mathbf{1 3}$ & $\mathbf{1 2}$ & $\mathbf{1 1}$ & $\mathbf{1 0}$ & $\mathbf{9}$ & $\mathbf{8}$ & $\mathbf{7}$ & $\mathbf{6}$ & $\mathbf{5}$ & $\mathbf{4}$ & $\mathbf{3}$ & $\mathbf{2}$ & $\mathbf{1}$ \\
\hline
\end{tabular}

\subsection{Assessment of atmospheric instability based on the detected hail diameter $>2 \mathrm{~cm}$}

Also, in the qualitative analysis is the study of storms with a hail potential of more than $2 \mathrm{~cm}$ in diameter. (Table 5)

Table 5. Atmospheric instability rank according to the number of storms with detected hail diameter $>2 \mathrm{~cm}$

\begin{tabular}{|c|c|c|c|c|c|c|c|c|c|c|c|c|c|c|c|c|c|c|}
\hline Year & 2004 & 2005 & 2006 & 2007 & 2008 & 2009 & 2010 & 2011 & 2012 & 2013 & 2014 & 2015 & 2016 & 2017 & 2018 & 2019 & Total & $\%$ \\
\hline error & 0 & 0 & 9 & 24 & 18 & 17 & 5 & 7 & 5 & 25 & 0 & 15 & 33 & 25 & 23 & 22 & 228 & 0,07 \\
\hline$<1,3 \mathrm{~cm}$ & 529 & 965 & 2752 & 2841 & 2348 & 2159 & 1777 & 3267 & 1912 & 3931 & 1627 & 2408 & 3418 & 2425 & 7375 & 4505 & 44239 & 14,44 \\
\hline $1.3 \mathrm{~cm}$ & 161 & 304 & 1446 & 1323 & 1285 & 890 & 990 & 1369 & 1139 & 2157 & 613 & 1058 & 1792 & 1386 & 4143 & 2956 & 23012 & 7,51 \\
\hline $1.9 \mathrm{~cm}$ & 71 & 102 & 658 & 450 & 548 & 337 & 461 & 529 & 567 & 948 & 219 & 413 & 914 & 627 & 1866 & 1573 & 10283 & $\mathbf{3 , 3 6}$ \\
\hline $2.5 \mathrm{~cm}$ & 32 & 30 & 294 & 139 & 189 & 127 & 308 & 214 & 338 & 461 & 85 & 172 & 468 & 352 & 830 & 864 & 4903 & $\mathbf{1 , 6 0}$ \\
\hline $3.2 \mathrm{~cm}$ & 15 & 21 & 146 & 55 & 98 & 53 & 140 & 123 & 200 & 236 & 21 & 77 & 257 & 195 & 400 & 471 & 2508 & $\mathbf{0 , 8 2}$ \\
\hline $3.8 \mathrm{~cm}$ & 9 & 9 & 68 & 23 & 33 & 29 & 81 & 45 & 118 & 170 & 3 & 49 & 177 & 105 & 215 & 265 & 1399 & $\mathbf{0 , 4 6}$ \\
\hline $4.5 \mathrm{~cm}$ & 4 & 0 & 35 & 13 & 28 & 10 & 45 & 32 & 87 & 105 & 4 & 17 & 105 & 66 & 133 & 172 & 856 & $\mathbf{0 , 2 8}$ \\
\hline $5.1 \mathrm{~cm}$ & 0 & 0 & 20 & 8 & 15 & 6 & 27 & 16 & 76 & 62 & 1 & 8 & 73 & 30 & 61 & 87 & 490 & $\mathbf{0 , 1 6}$ \\
\hline $5.7 \mathrm{~cm}$ & 1 & 0 & 15 & 7 & 3 & 4 & 15 & 7 & 58 & 33 & 0 & 9 & 53 & 32 & 41 & 64 & 342 & $\mathbf{0 , 1 1}$ \\
\hline $6.4 \mathrm{~cm}$ & 0 & 0 & 5 & 2 & 5 & 2 & 15 & 6 & 43 & 16 & 0 & 1 & 33 & 15 & 29 & 37 & 209 & $\mathbf{0 , 0 7}$ \\
\hline $7.0 \mathrm{~cm}$ & 0 & 0 & 5 & 0 & 3 & 0 & 9 & 5 & 28 & 16 & 0 & 0 & 31 & 17 & 11 & 21 & 146 & $\mathbf{0 , 0 5}$ \\
\hline $7.6 \mathrm{~cm}$ & 0 & 0 & 6 & 0 & 1 & 0 & 10 & 2 & 28 & 11 & 0 & 2 & 22 & 6 & 7 & 21 & 116 & $\mathbf{0 , 0 4}$ \\
\hline $8.3 \mathrm{~cm}$ & 0 & 0 & 1 & 0 & 1 & 0 & 7 & 2 & 12 & 6 & 0 & 0 & 22 & 7 & 5 & 6 & 69 & $\mathbf{0 , 0 2}$ \\
\hline $8.9 \mathrm{~cm}$ & 0 & 0 & 0 & 0 & 1 & 0 & 3 & 1 & 6 & 3 & 0 & 0 & 13 & 3 & 2 & 5 & 37 & $\mathbf{0 , 0 1}$ \\
\hline $9.5 \mathrm{~cm}$ & 0 & 0 & 1 & 0 & 1 & 0 & 1 & 0 & 4 & 1 & 0 & 0 & 12 & 7 & 1 & 2 & 30 & $\mathbf{0 , 0 1}$ \\
\hline $10.2 \mathrm{~cm}$ & 0 & 0 & 1 & 0 & 0 & 0 & 3 & 3 & 5 & 2 & 0 & 0 & 24 & 9 & 3 & 4 & 54 & $\mathbf{0 , 0 2}$ \\
\hline Without & 7090 & 10454 & 14354 & 12729 & 15669 & 12578 & 14891 & 16552 & 10810 & 16354 & 8734 & 15188 & 18037 & 11014 & 21457 & 11529 & 217440 & 70,98 \\
\hline Total & 7912 & 11885 & 19816 & 17614 & 20246 & 16212 & 18788 & 22180 & 15436 & 24537 & 11307 & 19417 & 25484 & 16321 & 36602 & 22604 & 306361 & 100 \\
\hline
\end{tabular}


Of the total number of storms detected by the weather radar, only $7 \%$ are storms that contain hail with the diameter greater than $2 \mathrm{~cm}$ (Table 5).

The rank assigned to each year does not have essential changes in the ranking, fixing on the positions especially the years at the top of the ranking (Table 6).

Table 6. Atmospheric instability rank according to the number of storms with the detected hail diameter $>2 \mathrm{~cm}$

\begin{tabular}{|c|c|c|c|c|c|c|c|c|c|c|c|c|c|c|c|c|}
\hline Year & 2018 & 2019 & 2016 & 2013 & 2012 & 2017 & 2006 & 2010 & 2011 & 2008 & 2015 & 2007 & 2009 & 2014 & 2005 & 2004 \\
\hline Storms with hail $>2 \mathrm{~cm}$ & 3604 & 3592 & 2204 & 2070 & 1570 & 1471 & 1255 & 1125 & 985 & 926 & 748 & 697 & 568 & 333 & 162 & 132 \\
\hline Rank & $\mathbf{1 6}$ & $\mathbf{1 5}$ & $\mathbf{1 4}$ & $\mathbf{1 3}$ & $\mathbf{1 2}$ & $\mathbf{1 1}$ & $\mathbf{1 0}$ & $\mathbf{9}$ & $\mathbf{8}$ & $\mathbf{7}$ & $\mathbf{6}$ & $\mathbf{5}$ & $\mathbf{4}$ & $\mathbf{3}$ & $\mathbf{2}$ & $\mathbf{1}$ \\
\hline
\end{tabular}

\subsection{Assessment of atmospheric instability}

The degree of atmospheric instability was obtained by summing radar characteristic products (hail diameter, reflectivity over $50 \mathrm{dBZ}$ etc.) and storms characteristics. After that, a rank for each sum was given, according to the methodology used (Table 7). The most unstable years using the parameters of the weather radar are: 2018, 2019, 2016, and the most stable are: 2004, 2005 and 2014.

Table 7. Atmospheric instability rank obtained from radar data

\begin{tabular}{|c|c|c|c|c|c|c|c|c|c|c|c|c|c|c|c|c|}
\hline Year & 2004 & 2005 & 2006 & 2007 & 2008 & 2009 & 2010 & 2011 & 2012 & 2013 & 2014 & 2015 & 2016 & 2017 & 2018 & 2019 \\
\hline No cores & 1 & 3 & 10 & 7 & 11 & 5 & 8 & 12 & 4 & 14 & 2 & 9 & 15 & 6 & 16 & 13 \\
\hline \begin{tabular}{|l|} 
No days \\
with $>640$ \\
storms
\end{tabular} & 1 & 2 & 12 & 11 & 8 & 7 & 10 & 9 & 5 & 13 & 3 & 4 & 14 & 6 & 16 & 15 \\
\hline $\begin{array}{l}\text { No days } \\
\text { with }>1200 \\
\text { storms } \\
\end{array}$ & 1 & 3 & 9 & 4 & 10 & 12 & 8 & 13 & 7 & 14 & 2 & 6 & 15 & 5 & 16 & 11 \\
\hline $\begin{array}{l}\text { Hail diameter } \\
>2 \mathrm{~cm}\end{array}$ & 1 & 2 & 9 & 4 & 6 & 5 & 11 & 8 & 12 & 13 & 3 & 7 & 15 & 10 & 14 & 16 \\
\hline \begin{tabular}{|l|} 
Reflectivity $>$ \\
$55 \mathrm{dBZ}$
\end{tabular} & 1 & 2 & 12 & 6 & 7 & 4 & 9 & 10 & 11 & 14 & 3 & 5 & 13 & 8 & 16 & 15 \\
\hline TOTAL & 5 & 12 & 52 & 32 & 42 & 33 & 46 & 52 & 39 & 68 & 13 & 31 & 72 & 35 & 78 & 70 \\
\hline Rank & 1 & 2 & 12 & 5 & 9 & 6 & 10 & 11 & 8 & 13 & 3 & 4 & 15 & 7 & 16 & 14 \\
\hline
\end{tabular}

\section{ASSESSMENT OF INSTABILITY BASED ON METEOROLOGICAL PARAMETERS}

In order to validate the method of establishing the degree of atmospheric instability using radar data, these were correlated with some meteorological parameters that are used in the forecast of atmospheric instability situations. As a result, with the help of the reanalysis data from https://www.esrl.noaa.gov/, the average monthly deviations were evaluated against the climatological norms, attributed to the north-western part of Romania, of the isotherms at the standard isobaric levels of $300 \mathrm{mb}$ respectively $850 \mathrm{mb}$ and of the geopotential at $500 \mathrm{mb}$. At the same time, an index of instability LI (lifted index) was analyzed. 


\subsection{Estimation of the degree of instability according to the deviation of the average monthly isotherms at geopotential height of $300 \mathrm{mb}$ and at $850 \mathrm{mb}$}

The years with positive deviations of the isotherms from at geopotential height of $300 \mathrm{mb}$ and $850 \mathrm{mb}$ in June are generally the most unstable. (Table 8)

Positive deviations imply a warmer weather and therefore, during the daytime warming, an increase in the intensity of convective processes, as a result of the overlapping years with warmer June over unstable years $(2018,2019,2016)$, and years with negative deviations over low instability $(2004,2005)$.In general, the ranks obtained from atmospheric instability and thermal deviation are generally close as values. There are some exceptions such as the years 2006 and 2017. The year 2006 with negative deviations is influenced by a period in which the cyclonic activity predominated in comparison with 2017 in which the anticyclones predominated. (Table 8 ).

Table 8. Estimation of the degree of atmospheric instability according to the deviation of the average monthly isotherms at $300 \mathrm{mb}$ and at $850 \mathrm{mb}$

\begin{tabular}{|c|c|c|c|c|c|c|c|c|c|c|c|c|c|c|c|c|}
\hline Year & 2004 & 2005 & 2006 & 2007 & 2008 & 2009 & 2010 & 2011 & 2012 & 2013 & 2014 & 2015 & 2016 & 2017 & 2018 & 2019 \\
\hline $\begin{array}{c}\text { Deviation at } 300 \mathrm{mb} \\
{ }^{0} \mathrm{C}\end{array}$ & $<-0.7$ & $<-0.7$ & $<-0.7$ & $<0.2$ & $>0.5$ & $>0.6$ & $>\mathbf{2 . 4}$ & $>0.8$ & $>\mathbf{2 . 0}$ & $=0.0$ & $<-0.4$ & $>0.3$ & $>\mathbf{1 . 0}$ & $>\mathbf{2 . 5}$ & $>\mathbf{2 . 0}$ & $>\mathbf{3 . 5}$ \\
\hline $\begin{array}{c}\text { Deviation aT850 mb } \\
{ }^{0} \mathrm{C}\end{array}$ & $<-0.6$ & $<-1.2$ & $=0$ & $>2.3$ & $>1.0$ & $>0.7$ & $>\mathbf{1 . 0}$ & $>0.7$ & $>\mathbf{1 . 5}$ & $>1.0$ & $<-0.6$ & $>0.6$ & $>\mathbf{2 . 0}$ & $>\mathbf{2 . 0}$ & $>\mathbf{1 . 5}$ & $>\mathbf{2 . 5}$ \\
\hline $\begin{array}{c}\text { Thermal deviation } \\
\text { rank }\end{array}$ & $\mathbf{2}$ & $\mathbf{1}$ & $\mathbf{4}$ & $\mathbf{5}$ & $\mathbf{1 0}$ & $\mathbf{7}$ & $\mathbf{1 1}$ & $\mathbf{8}$ & $\mathbf{1 2}$ & $\mathbf{9}$ & $\mathbf{3}$ & $\mathbf{6}$ & $\mathbf{1 4}$ & $\mathbf{1 5}$ & $\mathbf{1 3}$ & $\mathbf{1 6}$ \\
\hline $\begin{array}{c}\text { Instability rang } \\
\text { obtained from } \\
\text { radar data }\end{array}$ & $\mathbf{1}$ & $\mathbf{2}$ & $\mathbf{1 2}$ & $\mathbf{7}$ & $\mathbf{9}$ & $\mathbf{5}$ & $\mathbf{1 0}$ & $\mathbf{1 1}$ & $\mathbf{8}$ & $\mathbf{1 3}$ & $\mathbf{3}$ & $\mathbf{4}$ & $\mathbf{1 5}$ & $\mathbf{6}$ & $\mathbf{1 6}$ & $\mathbf{1 4}$ \\
\hline
\end{tabular}

\subsection{Estimation of the degree of instability according to the deviations of the average monthly geopotential height of $500 \mathrm{mb}$}

The average positive or negative deviations of the geopotential height at $500 \mathrm{mb}$ are related to cyclonic or anticyclonic activity. It was expected to have a correlation with the instability related to the negative deviations of the geopotential, so the most unstable years are the years with positive deviations 2019 (70 mgp), 2018 (30 mgp) and the least unstable years 2004, 2005 (-5 mgp) (Table 9).

Table 9. Estimation of the degree of atmospheric instability according to the deviations of the average monthly geopotential height at $500 \mathrm{mb}$

\begin{tabular}{|l|c|c|c|c|c|c|c|c|c|c|c|c|c|c|c|c|}
\hline $\begin{array}{l}\text { Year } \\
\begin{array}{l}\text { Thegeopotentialheight } \\
\text { deviation } \\
\text { averageat500 mb } \\
(\mathrm{m})\end{array}\end{array}$ & 2004 & 2005 & 2006 & 2007 & 2008 & 2009 & 2010 & 2011 & 2012 & 2013 & 2014 & 2015 & 2016 & 2017 & 2018 & 2019 \\
\hline $\begin{array}{l}\text { Geopotential height } \\
\text { rank }\end{array}$ & $\mathbf{2}$ & $\mathbf{3}$ & $\mathbf{8}$ & $\mathbf{9}$ & $\mathbf{1 1}$ & $\mathbf{4}$ & $\mathbf{7}$ & $\mathbf{5}$ & $\mathbf{1 5}$ & $\mathbf{6}$ & $\mathbf{1}$ & $\mathbf{1 0}$ & $\mathbf{1 2}$ & $\mathbf{1 4}$ & $\mathbf{1 3}$ & $\mathbf{1 6}$ \\
\hline $\begin{array}{l}\text { Instability } \\
\text { rankobtained from } \\
\text { radar data }\end{array}$ & $\mathbf{1}$ & $\mathbf{2}$ & $\mathbf{1 2}$ & $\mathbf{7}$ & $\mathbf{9}$ & $\mathbf{5}$ & $\mathbf{1 0}$ & $\mathbf{1 1}$ & $\mathbf{8}$ & $\mathbf{1 3}$ & $\mathbf{3}$ & $\mathbf{4}$ & $\mathbf{1 5}$ & $\mathbf{6}$ & $\mathbf{1 6}$ & $\mathbf{1 4}$ \\
\hline
\end{tabular}




\subsection{Estimation of the degree of atmospheric instability according to the value of $L I$ index}

It is a stability index used to determine the potential of the atmosphere to produce storms. Higher negative LI values indicate additional energy for the ascending particle. There are some average values of LI:

$>2=$ atmosphere is stable;

$[0,2)=$ atmosphere is weakly stable;

$[-2,0)=$ atmosphere is weakly unstable;

$<-2=$ atmosphere is moderately unstable.

It is observed that the years in which the value of LI is $<-2$ are the most unstable: 2018, 2016, 2019, 2013 and in the years with the lowest instability: 2004, 2005,2014 the value of LI is $>1$. The LI index proved to be a good indicator for establishing instability. (Table 10)

Table10. Estimation of the degree of atmospheric instability according to the value of LI index

\begin{tabular}{|l|c|c|c|c|c|c|c|c|c|c|c|c|c|c|c|c|}
\hline Year & 2004 & 2005 & 2006 & 2007 & 2008 & 2009 & 2010 & 2011 & 2012 & 2013 & 2014 & 2015 & 2016 & 2017 & 2018 & 2019 \\
\hline LI value & $>1$ & $>1$ & $(-2 ; 0)$ & $(-2 ; 0)$ & $(-2 ; 0)$ & $(0 ; 1)$ & $(0 ; 1)$ & $(-2 ; 0)$ & $(-2 ; 0$ & $<-2$ & $>1$ & $(0 ; 1)$ & $<-2$ & $(0 ; 1)$ & $<-2$ & $<-2$ \\
\hline LI rank & 1 & 2 & 11 & 12 & 10 & 6 & 7 & 9 & 8 & 15 & 3 & 4 & 14 & 5 & 13 & 16 \\
\hline $\begin{array}{l}\text { Instability } \\
\text { rankobtained } \\
\text { from radar } \\
\text { data }\end{array}$ & $\mathbf{1}$ & $\mathbf{2}$ & $\mathbf{1 2}$ & $\mathbf{5}$ & $\mathbf{9}$ & $\mathbf{6}$ & $\mathbf{1 0}$ & $\mathbf{1 1}$ & $\mathbf{8}$ & $\mathbf{1 3}$ & $\mathbf{3}$ & $\mathbf{4}$ & $\mathbf{1 5}$ & $\mathbf{7}$ & $\mathbf{1 6}$ & $\mathbf{1 4}$ \\
\hline
\end{tabular}

\section{CONCLUSIONS}

Compared to other data sources, the great potential of meteorological radar data for applied climatology results from its spatial and temporal resolution and coverage. Even if some specific problems arise when analyzing radar data for the purpose of climate study (systematic errors, lack of data, etc.), they can be managed through proper processing.

The results obtained from the study show a satisfactory correlation, especially at the interval ends. The most unstable years resulting from radar data are also the most unstable at the analysis of atmospheric instability $(2019,2016,2018)$ and the most stable $(204,2005,2014)$. (Table 11)

The differences appear in the middle area of the ranking and are the result of the monthly analysis. An analysis for each day could bring much better correlations, especially in the geopotential height field from $500 \mathrm{mb}$.

The analysis of the storms detected by the Doppler meteorological radar, both quantitatively and qualitatively, led to a refinement of the degree of instability of June from 2004 to 2019. 
Table 11. Correlation of the degree of instability obtained from radar data with the one that derived from the analysis of the atmospheric parameters considered

\begin{tabular}{|l|c|c|c|c|c|c|c|c|c|c|c|c|c|c|c|c|}
\hline Year & 2004 & 2005 & 2006 & 2007 & 2008 & 2009 & 2010 & 2011 & 2012 & 2013 & 2014 & 2015 & 2016 & 2017 & 2018 & 2019 \\
\hline $\begin{array}{l}\text { Instability } \\
\text { rank from } \\
\text { atmospheric } \\
\text { analysis }\end{array}$ & $\mathbf{1}$ & $\mathbf{2}$ & $\mathbf{7}$ & $\mathbf{9}$ & $\mathbf{1 1}$ & $\mathbf{4}$ & $\mathbf{8}$ & $\mathbf{6}$ & $\mathbf{1 3}$ & $\mathbf{1 0}$ & $\mathbf{3}$ & $\mathbf{5}$ & $\mathbf{1 5}$ & $\mathbf{1 2}$ & $\mathbf{1 4}$ & $\mathbf{1 6}$ \\
\hline $\begin{array}{l}\text { Instability } \\
\text { rankobtaine } \\
\text { d from } \\
\text { radar data }\end{array}$ & $\mathbf{1}$ & $\mathbf{2}$ & $\mathbf{1 2}$ & $\mathbf{5}$ & $\mathbf{9}$ & $\mathbf{6}$ & $\mathbf{1 0}$ & $\mathbf{1 1}$ & $\mathbf{8}$ & $\mathbf{1 3}$ & $\mathbf{3}$ & $\mathbf{4}$ & $\mathbf{1 5}$ & $\mathbf{7}$ & $\mathbf{1 6}$ & $\mathbf{1 4}$ \\
\hline
\end{tabular}

Thus, in the years with a close number of storms the difference was made by the intensity of the storms, several storms with reflectivity greater than $55 \mathrm{dBZ}$ or with hail.

\section{REFERENCES}

1. Berg P., Norn L. \& Olsson J. (2015): Creation of a high resolution precipitation data set by merging gridded gauge data and radar observations for Sweden. Journal of Hydrology, in press, DOI: 10.1016/j.jhydrol.2015.11.031. http://dx.doi.org/10.1016/j.jhydrol.2015.11.031 0022-1694/Ó 2015

2. Keupp L., Winterrath T., Hollmann R.(2017) Use of Weather Radar Data for Climate Data Records in WMO Regions IV and VI URL:https://www.wmo.int/pages/prog/wcp/ccl/opace/opace2/documents/TTURSDCM Use Remote Sensing DataClimateMonitoringRAIV-VI.pdf Accessed on 02.11.2019

3. URL: https://www.esrl.noaa.gov/ Accessed on 02.11.2019

4. URL: https://www.weatherwatch.net.au/weather/liftedindex/ Accessed on 02.11 .2019

5. *** radar history ANM Bucuresti, CMR Transilvania Nord (2004-2019) 